\title{
Research on the Teaching Mode Design of Management Courses Based on the Network Resource Utilization
}

\author{
X.Y. XU \\ School of Economy and Management, Shenyang Aerospace University, Shenyang, China
}

\begin{abstract}
The conflicts between Enterprise management practice development and the outdated courses are the features of management courses. How to use network resources to solve this problem is the focus of this paper. Through the network resources effectively compensated teaching materials, assignments, and case discussion, and the existing disadvantages in teaching, using network resources to change teaching design and teaching mode.
\end{abstract}

KEYWORD: Network resources; management courses; teaching mode

\section{THE FEATURES OF ECONOMICS AND MANAGEMENT COURSES}

The aims of Economics and Management curriculum design are to stimulate students' potential and creativity to solve practical problems, have the analytic skills required by related works. The stresses of management courses focus on practical aspects, and with abstraction feature. However, the development of information technology and Internet put forward a revolutionary challenge to the teaching content, such as traditional teaching mode, teaching methods. On internet all these things like teaching materials, case studies, answers to exercises are easy to be found. As a result, the students spent much time on searching instead of thinking. Network changed administered student attitudes for learning, they believe that the network can give them any materials they want, and thus dilute the importance of classroom teaching, and the class attendance enthusiasm. Thus administered courses are often known as the "empty, boring, logic is not strong, the lack of interesting theoretical analysis text". How to use the network resources rational and efficiently, how to improve the abstraction of theoretical teaching, what kind of measures can be used to promote students' attitude in class are major problems in this article. Based on rich network resources, and considering the discipline and teaching content features, this paper explores ways to establish a network of resource utilization for different categories of courses, promoting the effectiveness of innovation administered by classroom teaching.

\section{THE INFLUENCE FROM NETWORK RESOURCES TO MANAGEMENT COURSES TEACHING}

Internet has become an indispensable tool in people's daily lives, network information-rich, and easy to find. With the popularity of the network, the impact of network resources on classroom teaching absorbs more and more scholars' attention. Network resources are important sources for students to obtain information, knowledge, and resolve their doubts. Rational utilization of network resources helping to train and inspire students self-learning ability. Nowadays more than $95 \%$ students use network resources every day, such as online news, search for information, playing games, using chat tools for communication. But for the acquisition of knowledge and academic resources to find information on the Internet is often with strong perform task feature not by volunteer. Such as finding answers to questions posed by the teacher, assisted complete the relevant coursework. The theoretical auxiliary data understanding for, for less analysis of reading information on how these teachers to become effective use of network resources, innovative teaching mode entry point.

\section{ANALYSIS OF THE NETWORK RESOURCE UTILIZATION STATUS BY STUDENTS}

The investigation to network resources utilization is designed to guide students rational utilize network resources, to effectively promote the construction 
economics and management courses. In November and December 2013 survey questionnaire administered to students in a college of Shenyang. The questionnaire consisted of two parts: the course conditions and network resource utilization. Totally 96 interviewees joined in the investigation, involving specialty: e-commerce, logistics management and marketing; involves courses: International Trade Practice, statistics and enterprise resource planning. Three courses represent three categories: close combination with the actual curriculum; logical thinking strong curriculum; comprehensive, strong theoretical courses. Research issues involving, about the frequency used website, the main purpose of using online learning resources, the difficulties met in online learning resources, when the use of network resources assisted learning, the preference resources type.

The results for the first question, about the frequency used website, Professional related portal (Airui website, etc.) 8\%; search engine (google, Baidu library, etc.) $52 \%$, network communication platform (Baidu know, forums, QQ group, etc.) 17\%; Wikipedia Knowledge Base (wiki, etc.) 12\%; academic databases (CNKI, etc.) 3\%; others $8 \%$. Based on the above findings, we found the academic databases like CNKI earned less attention in teaching. Proposal, each course should read some relevant literature, different types of courses, teachers can use the literature in different degree. Reasons for doing so, can allow students to learn how to ask questions related to the course, so that students understand that a course is not just a textbook, but rather a collection of all the relevant reference books and literature.

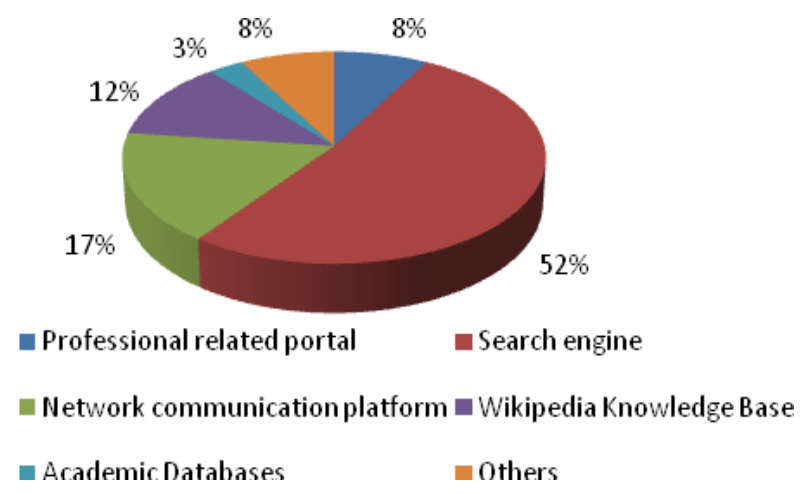

Figure 1. About the frequency used website

The results for the second question, the main purpose of using online learning resources, Expanding horizons of knowledge $12 \%$; cope with exam $23 \%$; complete teacher assignments $56 \%$; for research $2 \%$; knowledge sharing and exchange of $5 \%$; others $2 \%$. The distribution of the data, suggests that the teachers give the assignment with thoughtful design, more than $50 \%$ of students can improve network resource utilization effect.

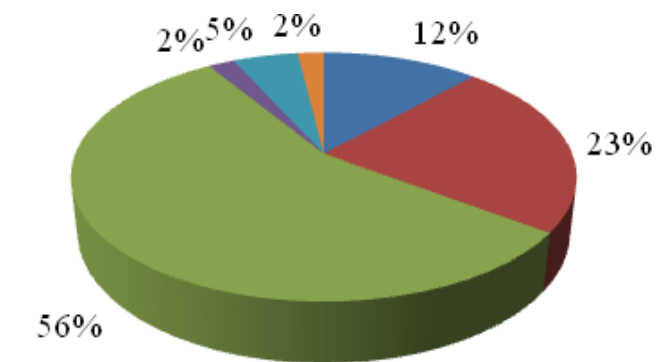

$$
\begin{aligned}
& \text { Expand the horizons of knowledge } \quad \text { Copewith exam } \\
& \text { Complete teacher assignments } \quad \text { For research } \\
& \text { Knowledge sharing and exchange } \quad \text { Others }
\end{aligned}
$$

Figure 2. The main purpose of using online learning resources

The results for the third question, the difficulties met in online learning resources, use encountered are, collect information is not comprehensive 7\%; do not know where to retrieve information, how to retrieve 32\%; retrieved, unable to download $28 \%$; unable to confirm whether the resources exist to find error 24 percent; other $9 \%$. This data results reflect the process of resource utilization in the network encountered one important question, that is the overall quality is not high, and low quality literature. This situation prompted us to teach students how to search materials, identify the need for good information to become a special training session.

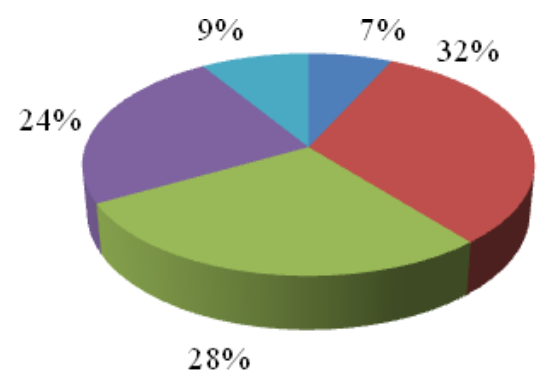

Collection of information is not comprehensive Do not know wher e to retrieve information, how to retrieve Retrieved, unable to download

Unable to confirm whether the resources exist to find error nothers

Figure 3. The difficulties met in online learning resources, use encountered

The results for the fourth question, when the use of network resources assisted learning, the preference resources type, Comparison table of basic concepts, formulas, principles, etc. $23 \%$; using the Internet materials to improve understandings to some keywords, the focus often repeated word, or new word often mentioned in the classroom $32 \%$; related cases, events, people, etc., which is closed to real life 39\%; others 6\%. These results indicate that students can use the Internet spontaneously, according to their actual knowledge of the background and hobbies independent study is good things. So the teachers can inspire the students in class with some new words to enhance students' 
interest in learning, especially emphasized keywords, focus on nouns, preferably linked to hot events, promote students understanding.

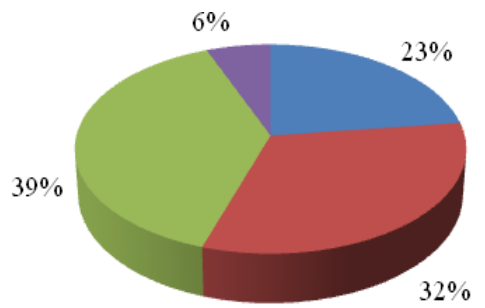

Comparison table of basic concepts, formulas, principles, etc.

U Using the Internet materials to improve understandings to some keywords, the focus often repeated word, or new word often mentionedin the classroom

- Related cases, events, people, etc., which is closed to real life

Others

Figure 4. When the use of network resources assisted learning, the preference resources type

\section{DESIGN THE MANAGEMENT COURSES TEACHING MODE BASED ON INTERNET RESOURCE UTILIZATION}

Teaching mode is a more stable framework or teaching activities program in a teaching theory to guide the formation. Based on the use of network resources, combined with the use of different information needs of the different feature of different course, how to use different types of network resources for teaching activities to design the management courses teaching mode based on internet resource utilization.

\subsection{The teaching mode design for closely to actual courses}

Linked closely with the actual curriculum such as international trade practice, business website design. For these courses, focusing on the use of network resources, thinking how to use network resources to enhance students' practical skills. Related to life can stimulate students' interest in learning greatly, improve their understanding of the theory in textbook. According to the teaching content, by integrate course content into an issue or topics discussed by students for creative thinking. Recommended research study mode based network resource utilization. Knowledge to establish a multithinking for methods, the ability and knowledge. This mode is for learners to provide rich learning resources, such as the use of role-playing method for a given case background, according to their interests, students need to collect relevant information, complete correlation analysis. Use network resources like news, current affairs and inspire thinking and ability to analyze problems to save time. Arouse students' curiosity and mystery, and create a good learning environment for students, so that they have a strong desire for knowledge and emotional resonance.

\subsection{The teaching mode design for Strong logic courses}

For these courses such as statistics, accounting, etc., how to master the use of network resources, features, search, screening, identification of high-value resources, expand the type of analysis of the problem has become the destination network resource utilization. Recommended personalized self-learning mode based network resource utilization. This pattern requires a clear teaching objectives, the students required to use network resources to aid understanding of the content, design their own notes format enhance learning efficiency.

With the development of mobile terminals, the behavior like searching information in classroom are very common now. Find information accounted for $80 \%$ of the time, the time spent in reading and learning is only $20 \%$. Eliminating the need for students to find time for information, read the information specified network, increase the proportion of reading analysis, not only limited to the level of searching. Teachers need to use the knowledge of the target and the ability to preestablished goals, carefully selected on the basis of the class, and provide a reference for student learning sequence, and schedule, so that students self-learning meet the teaching objectives, guiding students to master basic learning processes and interdisciplinary research methods.

\subsection{The teaching mode design for Comprehensive theoretical courses}

Such as enterprise resource planning, management and so on. Fully understand the actual using network resources, reduce the level of abstraction. To guide the main patterns to complete the information collection and integration, the use of classroom lectures plus student use of network resources finishing assignment. Arranging at least one or two lesson for introducing the relevant network resources, web site, and recommend relevant information, assist prep courses and exercises links. Ask the students to design at least five problems associated with this course. By this way broaden the learning scope. About easy-wrong point, some small traps designed to strengthen students' understanding degree to the key issues. Design divergence group, allow students to discuss thorough, broad thinking. Shared richness information, and give full play to the initiative of students. 


\section{REFERENCES}

[1] Wei Qing, ShongLing Li, YingMei Wu. Factors to explore the use of network resources, Shanxi Library Journal, 2010,119(4): 27-30
[2] Yan Li. Affecting College Students' use of computer analysis of network resources Obstacles, Open Education Research, 2008, 14(2):74-79.

[3] $\mathrm{Xu}$ Xianying, Research on case teaching mode building based on the familiar to content, Foreign Trade, 2013, 230(8):148-149. 